\title{
Can perceptual indices estimate physiological strain when wearing personal protective clothing in the heat?
}

\author{
David Borg*, lan Stewart, Joseph Costello \\ From 15th International Conference on Environmental Ergonomics (ICEE XV) \\ Portsmouth, UK. 28 June - 3 July 2015
}

\begin{abstract}
Introduction
Explosive ordnance disposal (EOD) often requires technicians to wear multiple protective garments in challenging environmental conditions. The accumulative effect of increased metabolic cost coupled with decreased heat dissipation associated with these garments predisposes technicians to high levels of physiological strain. It has been proposed [1] that a perceptual strain index (PeSI) using subjective ratings of thermal sensation and perceived exertion as surrogate measures of core body temperature and heart rate, may provide an accurate estimation of physiological strain. Therefore, this study aimed to assess if the PeSI could estmate the physiological strain index (PSI) across a range [2] of metabolic workloads and environments while wearing heavy EOD and chemical protective clothing.
\end{abstract}

\section{Methods}

Eleven healthy males wore an EOD and chemical protective ensemble while walking on a treadmill at $2.5,4$ or $5.5 \mathrm{~km} \cdot \mathrm{h}^{-1}$ at $1 \%$ grade in environmental conditions equivalent to wet bulb globe temperatures of $21^{\circ} \mathrm{C}, 30^{\circ} \mathrm{C}$ or $37^{\circ} \mathrm{C}$. Trials were ceased at a maximum of $60 \mathrm{~min}$ or until the attainment of termination criteria. A Pearson's correlation coefficient, mixed linear model, absolute agreement and receiver operating characteristic (ROC) curves were used to determine the relationship between the PeSI and PSI.

\section{Results}

A significant moderate relationship (Figure 1) between the PeSI and the PSI was observed $[r=0.77 ; p<0.001$;

\footnotetext{
* Correspondence: dn.borg@qut.edu.au

Institute of Health and Biomedical Innovation, Queensland University of Technology, Brisbane, Australia
}

\section{Discussion}

This is the first study to examine the ability of a PeSI to estimate physiological strain across a range of workloads and environments while wearing heavy protective clothing. The primary findings to emerge from this research are: (1) a statistically significant moderate relationship

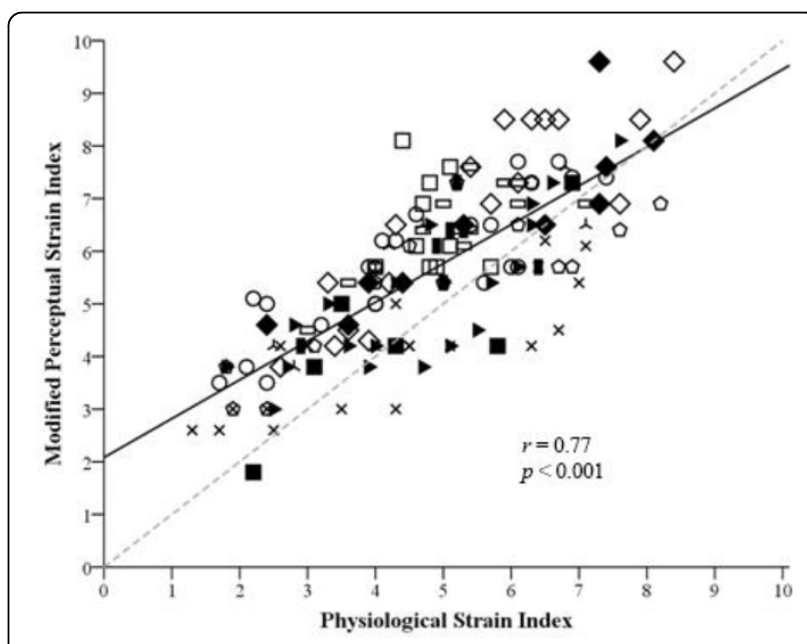

Figure 1 Regression of the PSI and the PeSI for all participants across all trials and time points. Solid line represents the trend line; each participant is represented by a unique symbol; the dashed line represents the line of identity. 
exists between the PeSI and PSI; and (2) the PeSI correctly or conservatively (over) estimated physiological strain $94.7 \%$ of the time.

\section{Conclusion}

These findings support the use of the PeSI for monitoring physiological strain whilst walking and wearing EOD and chemical protective clothing. However, future research is needed to confirm the validity of the PeSI for active EOD technicians operating in the field.

Published: 14 September 2015

\section{References}

1. Tikuisis P, McLellan TM, Selkirk G: Perceptual versus physiological heat strain during exercise-heat stress. Medicine and Science in Sports and Exercise 2002, 34:1454-1461

2. Moran D, Shitzer A, Pandolf K: A physiological strain index to evaluate heat stress. American Journal of Physiology 1998, 275:R129-R134.

doi:10.1186/2046-7648-4-S1-A144

Cite this article as: Borg et al:: Can perceptual indices estimate physiological strain when wearing personal protective clothing in the heat? Extreme Physiology \& Medicine 2015 4(Suppl 1):A144.
Submit your next manuscript to BioMed Central and take full advantage of:

- Convenient online submission

- Thorough peer review

- No space constraints or color figure charges

- Immediate publication on acceptance

- Inclusion in PubMed, CAS, Scopus and Google Scholar

- Research which is freely available for redistribution

Submit your manuscript at www.biomedcentral.com/submit 